\title{
BMJ Estimates of restrictive ventilatory Open defect in the mining industry. Considerations for epidemiological investigations: a cross-sectional study
}

\author{
Nnaemeka U Odo, ${ }^{1}$ Jeffrey H Mandel, ${ }^{1}$ David M Perlman, ${ }^{2}$ Bruce H Alexander, ${ }^{1}$ \\ Paul D Scanlon ${ }^{3}$
}

To cite: Odo NU, Mandel JH, Perlman DM, et al. Estimates of restrictive ventilatory defect in the mining industry. Considerations for epidemiological investigations: a crosssectional study. BMJ Open 2013;3:e002561. doi:10.1136/bmjopen-2013002561

- Prepublication history for this paper is available online. To view these files please visit the journal online (http://dx.doi.org/10.1136/ bmjopen-2013-002561).

Received 4 January 2013 Revised 12 June 2013 Accepted 14 June 2013

${ }^{1}$ Division of Environmental Health Sciences, University of Minnesota School of Public Health, Minneapolis, Minnesota, USA

${ }^{2}$ Division of Pulmonary, Critical Care, Allergy and Sleep Medicine, University of Minnesota Medical School, Minneapolis, Minnesota, USA ${ }^{3}$ Division of Pulmonary and Critical Care Medicine, Mayo Clinic, Rochester, Minnesota, USA

Correspondence to Jeffrey H Mandel; mand0125@umn.edu

\section{ABSTRACT}

Objectives: (1) To assess the impact of American Thoracic Society and European Respiratory Society (ATS/ERS) 'acceptability' and 'usability' criteria for spirometry on the estimates of restrictive ventilatory defect in a population of taconite miners. (2) To compare estimates of restrictive ventilatory defect with three different pulmonary function tests (spirometry, alveolar volume (VA) and diffusing capacity $\left(\mathrm{D}_{\mathrm{L}, \mathrm{CO}}\right)$ ). (3) To assess the role of population characteristics on these estimates.

Design: Cross-sectional study.

Setting: Current and former workers in six current taconite mining operations of northeastern Minnesota were surveyed.

Participants: We attempted to enrol 3313 participants. Of these, 1353 responded while 1188 current and former workers fully participated in the survey and 1084 performed complete pulmonary function testing and were assessed.

Primary and secondary outcome measures: We applied ATS/ERS acceptability criteria for all tests and categorised participants into groups according to whether they fully met, partially met or did not meet acceptability criteria for spirometry. Obstruction and restriction were defined utilising the lower limit of normal for all tests. When using VA, restriction was identified after excluding obstruction.

Results: Only $519(47.9 \%)$ tests fully met ATS/ERS spirometry acceptability criteria. Within this group, $5 \%$ had obstruction and $6 \%$, restriction on spirometry. In contrast, among all participants ( $N=1084), 16.8 \%$ had obstruction, while $4.5 \%$ had restriction. VA showed similar results in all groups after obstruction was excluded. Impaired gas transfer (reduced $\mathrm{D}_{\mathrm{L}, \mathrm{CO}}$ ) was identified in less than $50 \%$ of restriction identified by either spirometry or VA. Body mass index (BMI) was significantly related to spirometric restriction in all groups.

Conclusions: Population estimates of restriction using spirometry or VA varied by spirometric acceptability criteria. Other factors identified as important considerations in the estimation of restrictive ventilatory defect included increased BMI and gas transfer impairment in a relatively smaller proportion of

\section{ARTICLE SUMMARY}

\section{Article focus}

- Few studies have evaluated the impact of age, smoking and obesity on population estimates for restrictive disease within working populations.

- The hypothesis is that there is a difference in lung function between groups excluded by current spirometry guidelines and those that strictly meet all the acceptability criteria.

Key messages

- Spirometry plays a key role in respiratory health screening in occupational settings especially those with risk of lung disease.

- Estimates of restrictive ventilatory defect (RVD) vary by interpretation of acceptability criteria in population data.

- Future efforts to understand qualitative and quantitative exposure-disease relationships in miners require attention to these criteria to determine more representative lung disease estimates.

Strengths and limitations of this study

- This study combined results from three tests of pulmonary function in determining prevalence of RVD.

- Pulmonary function tests carried out in this study were used to estimate lung restriction in the absence of the ideal testing method, body plethysmography.

those with spirometric restriction. These insights are important when interpreting population-based physiological data in occupational settings.

\section{INTRODUCTION}

The determination of population estimates for restrictive ventilatory defect (RVD) within populations exposed to mining dusts typically relies upon the use of chest X-ray (CXR) and spirometry. Restrictive lung disease (RLD) 
refers to a decrease in total volume of the lungs due to impaired expansion from decreased lung elasticity. It is diagnosed using body plethysmography. It is a subset of what is actually measured, RVD which includes other causes of impaired expansion like decreased chest wall expansion and pulmonary vascular disease. In this paper, we measure RVD as an estimate for RLD. In the occupational setting, spirometry plays a key role in respiratory health surveillance. It can be performed on-site at low cost and with minimal risk to the employee. It can assist the health professional by determining if an individual worker demonstrates a specific pattern of respiratory impairment and in occupational settings, RVD. It can also help assess the effectiveness of measures implemented to protect the worker population and can help estimate exposure patterns to known hazards within working populations. ${ }^{1}$ An understanding of this exposure likelihood aids the interpretation of results from morbidity and mortality studies, particularly in the setting of absent or incomplete industrial hygiene information.

With the use of spirometry, the identification of RVD is complicated by several factors including low sensitivity/low positive-predictive value (PPV), variation in individual performance and the impact of confounding factors, particularly obesity and the effects of cigarette smoking. Few studies have evaluated the impact of these factors on population estimates for restrictive disease within working populations.

In clinic settings lung obstruction can be identified with high reliability and validity using the American Thoracic Society and European Respiratory Society (ATS/ERS) recommendations for spirometry. ${ }^{2-6}$ Assessing the presence of restriction can be more difficult with spirometry showing a higher negative than PPV in the identification of lung restriction $(\mathrm{PPV}<60 \%) .^{7-10}$ Ideally, it is suggested that after conducting spirometry, the presence of lung restriction should be further defined with the use of lung volume testing. ${ }^{8}{ }^{9}$ Given the problems of cost and access to lung volume testing, it has also been suggested that spirometry alone may be used to identify restriction without greatly compromising diagnostic accuracy. ${ }^{7} 811$ Other methods for assessing lung function may be helpful. These include the measurement of diffusing capacity $\left(\mathrm{D}_{\mathrm{L}, \mathrm{CO}}\right)$, and the measurement of alveolar volume (VA), which is carried out as a part of the $\mathrm{D}_{\mathrm{L}, \mathrm{CO}}$ test. VA, in the absence of obstruction, is more closely related to total lung capacity (TLC). ${ }^{6}{ }^{12-}$ ${ }^{14}$ Although these tests are often used to enhance diagnostic accuracy in clinical practice, they are not routinely available in most clinical or occupational settings. ${ }^{3}$

Individual spirometry measurement is effortdependent and quality of test performance is variable. Some of this variability can be related to underlying morbidity, which may affect an individual's ability to adhere to ATS/ERS criteria for acceptability. In epidemiological settings, these criteria may provide important insights into the impact of data quality on study results. For example, spirometry interpretation using 'acceptable' or 'usable' quality criteria can differentially exclude people with poor lung function from the assessment. ${ }^{5}$ Similar to the lack of data on spirometry quality and its impact on medical decisions, ${ }^{15}$ an in-depth look at spirometry use in mining populations has not been undertaken with these considerations in mind.

There were three primary objectives in this study. The first was to assess the impact of ATS/ERS 'acceptability' and 'usability' criteria on estimates of RVD in a population of taconite miners. The second was to compare estimates of RVD with three different pulmonary function tests (PFTs; spirometry, VA and (DL, CO). The third was to assess the role of population characteristics on these estimates.

\section{METHODS}

In 2010, a survey of current and former workers in the taconite mining industry of Minnesota was conducted as an attempt to quantify the types and severity of nonmalignant lung disease associated with exposure to dusts from mining operations. The survey included workers from all six current mining operations who were exposed after the 1950s (when workplace dust levels were likely higher than current levels) up to the present. A sample size of 1200 workers was selected to provide sufficient power to explore associations between lung function and exposures of interest and to determine the prevalence of lung pattern abnormality in the overall population of workers. ${ }^{16}$

With the help of union and company officials, we searched employment records to identify current and former miners in seven different Minnesota counties for recruitment to the study. The lists included workers who were employed at any time between 1989 and the present, regardless of when they started work. Individuals were contacted by mail or telephone and invited to participate. We obtained informed consent in accordance with a protocol approved by the University of Minnesota Human Subjects Research Committee.

Participants completed self-administered health and work questionnaires, underwent CXRs and PFTs which included spirometry and $\mathrm{D}_{\mathrm{L}, \mathrm{CO}}$ (with VA), in that order. Testing was performed at a community clinic in a location close to the miners' homes. Estimation of the prevalence of obstruction and RVD in this population of miners was made using current ATS/ERS criteria for all test methods. ${ }^{2-6}$ These criteria for spirometry testing included both criteria for acceptable blows, and criteria for manoeuvre repeatability.

\section{Standard approaches to measurement used}

The use of lower limits of normal (LLN) from reference equations has been shown to have a better combination of sensitivity, specificity and predictive values (positive and negative) as well as enhanced concordance and discordance when compared with the use of traditional 
cut-off points of $70 \%$ and $80 \%$ (for forced expiratory volume/forced vital capacity $\left(\mathrm{FEV}_{1} / \mathrm{FVC}\right)$ ratio, $\mathrm{FEV}_{1}$ and FVC percentage predicted). ${ }^{6}{ }^{17-20}$ Using the fifth centile LLN adjusts for age-related decline in lung function so that only $5 \%$ of individuals in each age reference group is labelled as 'abnormal.' In contrast, using $70 \%$ or $80 \%$ absolute cut-offs potentially results in an increased proportion of false positives in older participants. ${ }^{21}$

A $10.2 \mathrm{~L}$, dry rolling seal, volume displacement spirometer (Sensormedics 1022, Occupational Marketing Inc, Houston, Texas, USA) was used to conduct spirometry while an Ultima PF system (Medical Graphics Corporation, St Paul, Minnesota, USA) was used to conduct $\mathrm{D}_{\mathrm{L}, \mathrm{CO}}$ measurements. The latter uses singlebreath helium dilution for the measurement of VA. The ambient temperature was recorded automatically and barometric pressure was entered manually at the beginning of each test session. Screening spirometry was performed by technicians trained in a 2-day NIOSH-certified spirometry course. These technicians were also trained to perform $\mathrm{D}_{\mathrm{L}, \mathrm{CO}}$ testing. Precautions were taken to avoid errors. These included carrying out regular quality checks of equipment and monitoring the procedural performance of technicians. Testing followed ATS/ERS recommendations ${ }^{4}{ }^{5}$ except that here, five spirometry efforts were performed as a minimum.

Different categories based on meeting ATS/ERS guidelines on acceptability and repeatability of spirometric manoeuvres was assessed (table 1). Measurement of $\mathrm{D}_{\mathrm{L}, \mathrm{CO}}$ and VA were performed according to published guidelines. ${ }^{12} 22$ $\mathrm{D}_{\mathrm{L}, \mathrm{CO}}$ results met criteria if a participant had a minimum of three valid tests without exceeding five attempts. A valid test required a participant to hold their breath for 8-12 s with an Inspiratory Vital Capacity of $\geq 85 \%$ of Slow Vital Capacity. Repeatability criteria require that the best two $\mathrm{D}_{\mathrm{L}, \mathrm{CO}}$ results must be within $10 \%$ of each other. For data analysis, the average of the best two results was used.
Several standard reference equations for $\mathrm{FEV}_{1}$, FVC and $\mathrm{FEV}_{1} / \mathrm{FVC}$ have been developed for the general US population $^{23-27}$ and for the US blue collar workers. ${ }^{28} 29$ The reference equations of Hankinson $e t a t^{33}$ were used for the estimation of respective LLNs of the spirometric indices. In addition to being recommended by ATS/ERS as the best standard for US population assessment, ${ }^{4} 17$ Hankinson et al stratified their analysis by gender and age, covering a broad age range (8-80 years) and showed good agreement with previous reference equations. It has also been shown that these reference equations for spirometry may be applied to individuals older than 80 with low risk of misclassification. ${ }^{30}$

The current recommendations for interpretation in PFT were used. ${ }^{35617}$ A participant was identified as having 'airflow/lung/spirometric obstruction' if the $\mathrm{FEV}_{1} / \mathrm{FVC}$ ratio was $<\mathrm{LLN}$ and 'spirometric restriction' if their $\mathrm{FEV}_{1}$ / FVC ratio was normal $(\geq$ LLN) but their FVC value was $<\mathrm{LLN}$. A 'mixed pattern' was identified when both $\mathrm{FEV}_{1} /$ FVC ratio and FVC values were $<$ LLN. A 'mixed pattern' may be seen in individuals with obstruction plus either superimposed restriction or air trapping, either of which can lead to a reduction in FVC. 'All spirometric restriction' referred to estimates of spirometric restriction plus mixed pattern impairment identified in the population. Borderline obstruction, which may represent either a very mild obstruction or a normal physiological variant, sometimes called 'dysanapsis,' was identified by a low $\mathrm{FEV}_{1}$ / FVC ratio plus an $\mathrm{FEV}_{1} \geq$ LLN. $^{3} 561731$

Reference equations from Stocks and Quanjer ${ }^{32}$ were used for determining the LLN for VA as recommended by ATS/ERS. These were corrected for the anatomic dead space volume (VD) difference between VA and TLC. ${ }^{22} 33{ }^{34}$ For VD, when the body mass index BMI was $<30$, the formula: VD $(\mathrm{mL})=2.2 \times($ weight in $\mathrm{kg}$ ) was used, ${ }^{34}$ while when BMI was $\geq 30$ the formula: VD (mL) $=24 \times(\text { height in } \mathrm{cm})^{2} / 4545$ was used..$^{22}$ Reference values for $\mathrm{D}_{\mathrm{L}, \mathrm{CO}}$ from Crapo et al were utilised as

Table 1 Different categories based on meeting ATS/ERS guidelines on acceptability and repeatability of spirometric evaluations

\begin{tabular}{|c|c|c|c|}
\hline Participant manoeuvre & Category & Frequency & Percentage \\
\hline One acceptable manoeuvre only & 1 & 33 & 3 \\
\hline Two acceptable, repeatable manoeuvres only & 2 & 45 & 4.2 \\
\hline Two acceptable, not repeatable & 3 & 27 & 2.5 \\
\hline Two highest acceptable not repeatable* & 4 & 41 & 3.8 \\
\hline No plateau end-point reached & 5 & 384 & 35.4 \\
\hline No acceptable manoeuvre & 6 & 7 & 0.6 \\
\hline Not repeatable (3 acceptable manoeuvres) $†$ & 7 & 28 & 2.6 \\
\hline Meets ATS criteria & 8 & 519 & 47.9 \\
\hline Total & & 1084 & 100 \\
\hline \multicolumn{4}{|c|}{$\begin{array}{l}\text { 'No plateau end-point reached' referred to the inability to achieve end-of-test volume (EOTV), an important end-of-test (EOT) criterion. In this } \\
\text { case, the volume-time plateau was not obtained. } \\
\text { *Attained three acceptable manoeuvres but, as per criteria, the two highest values were not repeatable. The lower two were repeatable and } \\
\text { their values were used. } \\
\text { †Attained three acceptable manoeuvres but, as per criteria, none were repeatable. } \\
\text { ATS/ERS, American Thoracic Society and European Respiratory Society. }\end{array}$} \\
\hline
\end{tabular}


recommended by ATS/ERS, ${ }^{6} 2235$ with an adjustment for haemoglobin. ${ }^{6} 2236$

\section{Other definitions used}

We used the term 'VA restriction' when the $\mathrm{FEV}_{1} / \mathrm{FVC}$ ratios were normal ( $\geq \mathrm{LLN})$ and the VA was reduced, independently of FVC. This was carried out because previous studies have shown that, in the presence of lung obstruction, lung volume measured by single-breath helium dilution underestimates TLC measured by body plethysmography (VL, pleth). ${ }^{6}{ }^{13}{ }^{14}$ These obstructive scenarios include cysts, non-communicating bullae/airspaces and pneumothorax and are not incorporated in the single-breath helium estimate of lung volume (VA). ${ }^{6} 13$ However, when obstruction is excluded, lung volume estimation by single-breath helium dilution approximates VL, pleth. ${ }^{12-14} 37$ For $\mathrm{D}_{\mathrm{L}, \mathrm{CO}}$ estimations, the term 'low $\mathrm{D}_{\mathrm{L}, \mathrm{CO}}$ without obstruction' was used when $\mathrm{D}_{\mathrm{L}, \mathrm{CO}}$ was reduced $(<\mathrm{LLN})$ but the $\mathrm{FEV}_{1} / \mathrm{FVC}$ ratio was normal $(\geq \mathrm{LLN})$.

Participants were categorised into four non-exclusive groups (table 2) defined by the extent to which ATS/ERS criteria for spirometric performance were met. Group 1 ('Total group') includes all tested participants. Group 3 ('Met criteria') comprises participants who met all criteria for acceptability and repeatability. ${ }^{5}$ Group 2 ('Exclusions') includes those who failed any of the criteria (groups 2 and 3 were mutually exclusive). Group 4 ('Usable') uses relaxed acceptability criteria and can be thought of as allowing 'usable' tests as described by ATS/ ERS and included all participants from group 3 and some from group 2. These 'usable' tests were (1) tests with quality control grades of $\geq$ 'B' (at least two acceptable manoeuvres with $\mathrm{FEV}_{1}$ values repeatable within 101$150 \mathrm{~mL})^{17}$ and (2) tests that did not meet end-of-test (EOT) criteria (no plateau end-point reached). The assigned FVC values in this group (no plateau end-point reached) were likely close to true FVC values that would have been attained if plateau had been reached. The EOT criteria for acceptability are related to being unable to continue further exhalation and having a volume-time curve showing no change in volume $(<0.025 \mathrm{~L})$ for $\geq 1 \mathrm{~s}$ and an expiratory time $\geq 6 \mathrm{~s}^{5}{ }^{38}$

Although the other tests (VA and DL,CO) have unique criteria for acceptability which we adhered to, we formed groups on the basis of spirometry testing only. We were most interested in spirometric classification because it is the test most available in occupational settings. $\mathrm{D}_{\mathrm{L}, \mathrm{CO}}$ testing as well as spirometry are effort dependent, while $\mathrm{D}_{\mathrm{L}, \mathrm{CO}}$ (and VA) has the drawback of performing inconsistently in the presence of lung obstruction.

Description of the different groups was carried out and the only two mutually exclusive groups (groups 2 and 3) were compared using $\mathrm{t}$ test and $\chi^{2}$ analysis. Crude prevalence estimates of obstruction and restriction by spirometry were determined. Exact (Clopper-Pearson) 95\% CIs

Table 2 Demographic characteristics of four test groups

\begin{tabular}{|c|c|c|c|c|}
\hline Parameters & $\begin{array}{l}\text { Group } 1 \text { (total group) } \\
(n=1084)\end{array}$ & $\begin{array}{l}\text { Group } 2 \text { (exclusions) } \\
(n=565)\end{array}$ & $\begin{array}{l}\text { Group } 3 \text { (met criteria) } \\
(n=519)\end{array}$ & $\begin{array}{l}\text { Group } 4 \text { (usable) } \\
(n=989)\end{array}$ \\
\hline BMI* $^{*}$ & $31.4(5.4) \dagger$ & $31.2(5.2) \dagger$ & $31.6(5.6) \dagger$ & $31.4(5.4) \dagger$ \\
\hline$<18.5$ & 0.2 & 0.2 & 0.2 & 0.2 \\
\hline $18.5-25$ & 8.0 & 7.6 & 8.6 & 8.2 \\
\hline $25-29.9$ & 37.6 & 39.6 & 35.5 & 37.5 \\
\hline $30-34.9$ & 32.6 & 31.3 & 33.4 & 32.4 \\
\hline $35-39.9$ & 13.7 & 14.0 & 13.9 & 14.0 \\
\hline$\geq 40$ & 7.9 & 7.3 & 8.4 & 7.7 \\
\hline Age & $59.7(10.8) \dagger$ & $62.2(9.9) \dagger$ & $57.0(11.1) \dagger$ & $59.2(10.7) \dagger$ \\
\hline$<50$ & 16.5 & 9.6 & 22.9 & 17.3 \\
\hline $50-64$ & 49.2 & 46.9 & 51.2 & 50.1 \\
\hline $65-79$ & 31.4 & 40.5 & 22.9 & 29.9 \\
\hline$>79$ & 2.9 & 3.0 & 3.1 & 2.7 \\
\hline \multicolumn{5}{|l|}{ Smoking } \\
\hline Never & 38.0 & 27.5 & 48.4 & 37.8 \\
\hline Current & 12.0 & 14.9 & 9.2 & 12.5 \\
\hline Former & 50.0 & 57.6 & 42.4 & 49.7 \\
\hline \multicolumn{5}{|l|}{ Gender } \\
\hline Female & 9.3 & 4.4 & 14.6 & 9.9 \\
\hline Male & 90.7 & 95.6 & 85.4 & 90.1 \\
\hline
\end{tabular}

All values were percentage distributions of each parameter within the population groups.

Group 1-all workers surveyed without consideration for exclusion based on ATS/ERS test criteria for spirometry.

Group 2-all workers who did not meet all ATS/ERS criteria for spirometric assessment.

Group 3-workers who met all ATS/ERS criteria for spirometric assessment.

Group 4-All workers with spirometry quality $\geq$ "B" (see Methods section) and repeatable tests not meeting end-of-test (EOT) criteria.

${ }^{*} \mathrm{BMl}$ - weight in kilograms/height in metres squared $\left(\mathrm{kg} / \mathrm{m}^{2}\right)$.

†These represented the mean and SDs (in parenthesis) for these groups.

ATS/ERS, American Thoracic Society and European Respiratory Society; BMI, body mass index. 
were derived for the all estimates of lung function impairment. This method has the advantage of calculating conservative CI estimates when assessing binomial proportions. Prevalence estimates of RVD determined by combining tests were presented to show increased likelihood of restriction determination (table 3). ${ }^{6}$ The combination of these three tests also represented the lower bound for RVD prevalence estimates. When estimates were based on any of the three tests being abnormal ("Or"), this represented the upper bound for RVD estimates.

To explore the impact of obesity on the apparent prevalence of restriction in this population, we performed a multivariate analysis to determine the association of BMI with FVC. For this analysis, FVC was converted to a percentile value for each participant based on normal reference equations. ${ }^{23}$ This centile is the FVC of each participant, standardised to the NHANES III population-based distribution of normal lung function. This is different from percentage predicted which is a ratio of the FVC to the median predicted value for each participant (race, age, height and gender adjusted). This association was determined with a generalised linear model both unadjusted and adjusted for age and gender in all the described groups.

\section{RESULTS}

We attempted to enrol 3313 potential participants. A total of 1353 participants responded and provided consent and questionnaire information and of these, 1188 current and former workers fully participated in the survey. Of the 1188 workers, 1084 performed complete pulmonary function testing. Their data comprised the data set analysed for this assessment.

The participants lived in seven different counties in northeastern Minnesota and ranged in age from 36 to 89 years with a mean age of 59.7 years ( $\mathrm{SD}=10.8$ years). Most participants were men $(90.7 \%)$, with current smokers comprising 12\%, never-smokers, $38 \%$ and former smokers, $50 \%$ of the population tested. Of the 1084 participants assessed, $519(47.9 \%)$ fully met ATS/ ERS criteria of three acceptable and two repeatable manoeuvres for spirometry. ${ }^{5}$ The others had criteria for exclusion as shown in table 1 . Of the tests that were potentially excluded, the majority were due to failure to meet EOT criteria by reaching an adequate plateau. ${ }^{5}$ This latter category comprised $68 \%$ of potentially excluded tests.

Table 2 shows the demographics of all groups. While BMI was distributed similarly among all groups, group 3 was younger, had a higher proportion of women and a higher proportion of individuals who had never smoked.

Table 3 Prevalence estimates of lung function patterns in different groups

\begin{tabular}{|c|c|c|c|c|c|c|c|c|}
\hline \multirow[b]{3}{*}{$\mathbf{N}$} & \multirow{2}{*}{\multicolumn{2}{|c|}{$\begin{array}{l}\text { Group } 1 \\
\text { (total group) } \\
1084\end{array}$}} & \multirow{2}{*}{\multicolumn{2}{|c|}{$\frac{\text { Group } 2 \text { (exclusions) }}{565}$}} & \multirow{2}{*}{\multicolumn{2}{|c|}{$\begin{array}{l}\text { Group } 3 \\
\text { (met criteria) } \\
519\end{array}$}} & \multirow{2}{*}{\multicolumn{2}{|c|}{$\begin{array}{l}\text { Group } 4 \\
\text { (usable) }\end{array}$}} \\
\hline & & & & & & & & \\
\hline & Per cent & $95 \% \mathrm{Cl}$ & Per cent & $95 \% \mathrm{Cl}$ & Per cent & $95 \% \mathrm{Cl}$ & Per cent & $95 \% \mathrm{Cl}$ \\
\hline Spirometric obstruction* & 16.8 & 14.6 to 19.2 & 27.6 & 24.0 to 31.5 & 5.0 & 3.3 to 7.3 & 17.6 & 15.3 to 20.1 \\
\hline Spirometric restriction* & 4.5 & 3.4 to 5.9 & 3.2 & 1.9 to 5.0 & 6.0 & 4.1 to 8.4 & 3.9 & 2.8 to 5.4 \\
\hline Mixed disease* & 2.9 & 2.0 to 4.0 & 4.6 & 3.0 to 6.7 & 1.0 & 0.3 to 2.2 & 2.9 & 2.0 to 4.2 \\
\hline All spirometric restriction* & 7.4 & 5.8 to 9.1 & 7.8 & 5.7 to 10.3 & 6.9 & 4.9 to 9.5 & 6.9 & 5.4 to 8.6 \\
\hline VA restriction* & 5.9 & 4.6 to 7.5 & 5.0 & 3.3 to 7.1 & 6.9 & 4.9 to 9.5 & 5.7 & 4.3 to 7.3 \\
\hline $\begin{array}{l}\text { Low } D_{\mathrm{L}, \mathrm{CO}} \text { without } \\
\text { obstruction* }\end{array}$ & 9.0 & 7.4 to 10.9 & 8.3 & 6.2 to 10.9 & 9.8 & 7.4 to 12.7 & 9.2 & 7.5 to 11.2 \\
\hline Spirometry \& VA† & 2.6 & 1.7 to 3.7 & 1.8 & 0.9 to 3.2 & 3.5 & 2.1 to 5.4 & 2.4 & 1.6 to 3.6 \\
\hline Spirometry \& $D_{L, c o} \ddagger$ & 1.3 & 0.7 to 2.2 & 0.7 & 0.2 to 1.8 & 1.9 & 0.9 to 3.5 & 1.2 & 0.6 to 2.1 \\
\hline VA \& $D_{L, C O} \S$ & 2.3 & 1.5 to 3.4 & 1.4 & 0.6 to 2.8 & 3.3 & 1.9 to 5.2 & 2.3 & 1.5 to 3.5 \\
\hline Spirometry \& VA \& $D_{L, c o l l}$ & 1.1 & 0.5 to 1.9 & 0.5 & 0.1 to 1.5 & 1.7 & 0.8 to 3.3 & 1.0 & 0.5 to 1.9 \\
\hline Spirometry or VA** & 7.8 & 6.3 to 9.6 & 6.4 & 4.5 to 8.7 & 9.4 & 7.1 to 12.3 & 7.2 & 5.7 to 9.0 \\
\hline Spirometry or $\mathrm{D}_{\mathrm{L}, \mathrm{co}} \dagger \dagger$ & 12.3 & 10.4 to 14.4 & 10.8 & 8.4 to 13.7 & 13.9 & 11.0 to 17.2 & 11.9 & 10.0 to 14.1 \\
\hline VA or $D_{\mathrm{L}, \mathrm{co}} \neq \ddagger$ & 12.6 & 10.7 to 14.8 & 11.9 & 9.3 to 14.8 & 13.5 & 10.7 to 16.7 & 12.5 & 10.5 to 14.8 \\
\hline Spirometry or VA or $\mathrm{D}_{\mathrm{L}, \mathrm{co}} \S \S$ & 14.4 & 12.6 to 16.6 & 13.1 & 10.4 to 16.2 & 15.8 & 12.8 to 19.2 & 13.9 & 11.8 to 16.2 \\
\hline \multicolumn{9}{|c|}{$\begin{array}{l}\text { Per cent-prevalence of lung function patterns in each population group in percentage. } \\
95 \% \mathrm{Cl}-\text { Clopper-Pearson (exact) } 95 \% \text { confidence limits of prevalence estimates. }\end{array}$} \\
\hline
\end{tabular}


Comparison of groups 2 and 3 ('Exclusions' vs 'Met criteria') showed a significantly higher mean testing age in group 2, a higher proportion of men, a higher mean $\mathrm{FEV}_{1}$ and a significantly higher proportion of ever smokers (current and former). All $\mathrm{p}$ value estimates were $<0.0001$ and mean BMI was not significantly different between the two groups.

Table 3 presents the lung abnormality estimates for obstruction and RVD by spirometry, restriction by VA restriction and mixed disease by spirometry for all groups. It also presents estimates of abnormal lung function characterised by a $\mathrm{D}_{\mathrm{L}, \mathrm{CO}}<\mathrm{LLN}^{6}$ (low $\mathrm{D}_{\mathrm{L}, \mathrm{CO}}$ without obstruction) after patients with obstruction on spirometry were excluded. Estimation of the prevalence of restriction using VA ranged from $5 \%$ to $6.9 \%$ across the different groups. Estimation of RVD using spirometry had a wider range across the four groups ranging from $3.2 \%$ to $6 \%$. When participants with a mixed pattern were included, the range of estimates of RVD $(\mathrm{FVC}<\mathrm{LLN})$ across these four groups were less (6.9$7.8 \%)$. Spirometric obstruction varied the most, ranging from $5 \%$ to $27.6 \%$ depending on adherence to ATS/ ERS guidelines. Prevalence estimates of RVD using a combination of available tests ranged from $0.5 \%$ in group 2 using the ' $\&$ ' classification and all the tests to $9.4 \%$ in group 3 using the 'Or' classification for all the tests (after excluding obstruction).

BMI was $\geq 30$ in $54.2 \%$ of study participants. In table 4 , BMI was significantly associated with FVC percentiles in all four groups when unadjusted or adjusted for age and gender $(p<0.0001)$. BMI was observed to account for $8.8-9.2 \%$ of variation in percentile values when unadjusted. When adjusted for age and gender, this range increased to $9.3-10.6 \%$ with the highest value seen in group 3. The association in adjusted as well as unadjusted models demonstrated a trend of decreasing FVC percentile with increased BMI.

\begin{tabular}{|c|c|c|}
\hline Test criteria groups & Estimate & $\mathbf{R}^{2}(\%)$ \\
\hline otal group) & & \\
\hline ) & & \\
\hline & & \\
\hline Group 4川 (usable) & -0.017 & 8.8 \\
\hline \multicolumn{3}{|c|}{$\begin{array}{l}\text { All crude and multivariate linear regression models had significant } \\
\text { p values at }<0.0001 \text {. } \\
\text { Multivariate models involved adjusting for age and gender. } \\
\text { Groups are as described in the Methods Section. } \\
\text { *centiles of spirometry performance are expressed as the FVC of } \\
\text { each participant, standardised to the NHANES III } \\
\text { population-based distribution of normal lung function. This is } \\
\text { different from percentage predicted which is the ratio of the FVC to } \\
\text { the median predicted value for each participant (race, age, height } \\
\text { and gender adjusted). } \\
\text { †Adjusted estimate: }-0.018 ; \mathrm{R}^{2}(\%): 9.5 \text {. } \\
\text { †Adjusted estimate: }-0.019 ; \mathrm{R}^{2}(\%): 9.5 \text {. } \\
\text { §Adjusted estimate: }-0.016 ; \mathrm{R}^{2}(\%): 10.6 \text {. } \\
\text { ПAdjusted estimate: }-0.017 ; \mathrm{R}^{2}(\%): 9.3 \text {. } \\
\text { FVC, forced vital capacity. }\end{array}$} \\
\hline
\end{tabular}

\section{DISCUSSION}

The use of pulmonary function testing to estimate the prevalence of RVD in a dust-exposed population of workers has uncertainties about it. These uncertainties relate to individual performance on testing, testing errors, group characteristics of the participants tested and representativeness of the group tested. The focus of this investigation was to highlight the potential range of estimates of lung impairment depending on how spirometry acceptability criteria were applied and by the different PFTs used while considering population characteristics.

The overall response rate in this study was $40.8 \%$. We would expect similar factors to affect variability in estimates of RVD despite the degree of study participation. Estimates could vary upwards or downwards depending on the degree of underlying illness within the study participants.

The application of spirometry acceptability criteria to test results was an important factor in assessing abnormality. Acceptability criteria for spirometry impacted the prevalence estimates for RVD, especially lung obstruction and, consequently, mixed disease. Our assessment showed a high prevalence of obstructive patterns in those not meeting acceptability criteria, compared with those fully meeting criteria $(27.6 \%$ vs $5 \%)$. Identifying lung obstruction in this mining population is relevant because of the recognised role of heavy dust exposure in causing lung obstruction (non-pneumoconiotic effect).

A key criterion for the recommended exclusion of spirometric manoeuvres ('acceptable' vs 'usable') was not meeting EOT criteria. Among the participants, $35.4 \%$ (68\% of potentially excluded tests) did not meet EOT criteria for acceptability. Current ATS/ERS guidelines recommend not using manoeuvres or not meeting all acceptability criteria except where they may still contain useful information ('usable' manoeuvres). ${ }^{5}$ This recommendation referred to assessments for morbidity important for clinical care of patients. In this epidemiological assessment, most test curves not meeting EOT criteria were repeatable and represented the participants' best performance. Even though EOT criteria were not met, these results were included in groups 1, 2 and 4. Group 3 excludes these results. We regarded them as a necessary inclusion for epidemiological assessment (group 4), meeting the 'usability' criteria. Including these tests (not meeting EOT criteria) increased test success from $47.9 \%$ to $83.3 \%$. The diagnosis of 'true restriction' (RLD) is usually based on demonstrating a reduced TLC measured by body plethysmography (VL, pleth). This is considered the gold-standard for the diagnosis of RLD. ${ }^{3} 681739$ This test is not widely available in occupational or clinical settings, is costly and not portable. ${ }^{3}$ Though some studies have shown VL,pleth to be comparable to lung volume measured by single-breath helium dilution (VA), current guidelines point out that VA underestimates TLC in the setting of moderate-to-severe obstructive disease. ${ }^{6}{ }^{9} 12-14$ This is a 
key limitation of using VA as an approximate for TLC. For these reasons, use of VA (and $\mathrm{D}_{\mathrm{L}, \mathrm{CO}}$ ) in this study was limited to participants without obstruction $\left(\mathrm{FEV}_{1} /\right.$ FVC $\geq$ LLN). In the same subpopulation in all four groups (after excluding obstruction), VA restriction proportion was consistently higher than spirometric restriction proportion. This is thought to reflect the higher PPV of VA than spirometry in detecting restriction.

With our inclusion of tests not meeting EOT criteria, VA restriction could have included some participants with obstruction. The addition of $\mathrm{D}_{\mathrm{L}, \mathrm{CO}}$ to spirometry increases the accuracy of functional lung disease determination. ${ }^{6}$ It further characterises restriction identified by spirometry by providing a quantitative measure of gas transfer in the lungs. ${ }^{32}$ In this study, the prevalence of 'low $\mathrm{D}_{\mathrm{L}, \mathrm{CO}}$ without obstruction' was higher than 'VA restriction' in all groups. While $\mathrm{D}_{\mathrm{L}, \mathrm{CO}}$ may be a sensitive indicator of early interstitial lung disease, it is not a measure of lung volume. It is rather, a product of $\mathrm{D}_{\mathrm{L}, \mathrm{CO}}$ /VA ratio and VA. $\mathrm{D}_{\mathrm{L}, \mathrm{CO}}$ can also be abnormal in conditions unrelated to dust exposure such as pulmonary vascular abnormality (eg, pulmonary hypertension), or early emphysema not detected by spirometry. ${ }^{6} 243340$ It may also be falsely reduced by maldistribution of inspired gas when measuring VA in obstructive disorders. ${ }^{22}$ A systematic error in measurement using VA and $\mathrm{D}_{\mathrm{L}, \mathrm{CO}}$ was also possible since they are measured using similar technique (single-breath gas dilution) and on the same manoeuvre.

Although smoking does not result in RVD, the high prevalence of current and former smokers in this cohort could result in a greater estimate of mixed disease. Including the mixed category increases the estimate of RVD and is important for assessing restriction on that basis. Groups 2 and 3 represent the most disparate estimates for RVD, likely due to the higher prevalence (group 2) versus the lower prevalence (group 3) of mixed disease. The group 2 participants were shown to be significantly older than group 3, had significantly higher male proportions and higher amounts of current/former smoking.

The variation in estimates of abnormality across groups and the uniqueness of the potentially excluded group (group 2) highlights the problems of accurately estimating abnormality prevalence in the total group of workers. If only assessments that strictly met all ATS/ ERS acceptability criteria were used, many older and potentially sicker participants' tests would not be utilised, resulting in a biased estimate of the prevalence of RVD. Overall, the prevalence estimates determined using group 4 reflected a reasonable compromise in the application of ATS/ERS acceptability criteria. This assumes that the differences in obstruction prevalences observed between groups 3 and 4 represent the sicker, older miners, as suggested by the differences in mean age, BMI and current smoking proportions. Group 4 contained tests not meeting EOT criteria but were still usable in determining prevalence estimates. Exclusion of the potentially sicker population is avoided (group 3), while still excluding tests of poor quality, which group 1 would include. The minor differences in abnormality estimates between groups 1 and 4 may be accentuated in populations with a higher burden of underlying disease.

The prevalence of RVD determined with either spirometry or VA in combination ('\&') with isolated reduction in $\mathrm{D}_{\mathrm{L}, \mathrm{CO}}$ represented RVD likely caused by interstitial lung disease (see footnotes in table 3 for test combinations). The results showed that RVD with impaired gas transfer $\left(\mathrm{D}_{\mathrm{L}, \mathrm{CO}}<\mathrm{LLN}\right)$ represented less than $50 \%$ of estimated lung restriction by either spirometry or VA or both, together. This suggests that more than $50 \%$ of estimated restriction (by spirometry or VA) may be from extrapulmonary causes not affecting gas transfer in the lungs (eg, obesity). The effect of using multiple tests, including VA and $\mathrm{D}_{\mathrm{L}, \mathrm{CO}}$, should enhance the estimates of RVD. ${ }^{8}$

The effect of obesity on the apparent prevalence of RVD in an occupational group with dust exposure has obvious implications in studying such populations. Obesity can result in chest wall restriction that can affect the estimation the prevalence of RVD. In this study, $10 \%$ of the variation in FVC was accounted for by BMI. This is not surprising given the high percentage of overweight participants across all acceptability groups.

The estimate of restriction with spirometry was closest to the VA estimate of restriction in group 3. In this group, restriction estimates from the combination of Spirometry, VA and $\mathrm{D}_{\mathrm{L}, \mathrm{CO}}$ likely represented the best estimate of true lung restriction. It comprises the least amount of obstruction, while theoretically better approximating TLC. This insight, along with the ease of administration suggests that spirometry is a reasonable approach for the identification of lung restriction in this setting, particularly when taking chest wall issues, like obesity, into account. Since spirometry is commonly used in assessing lung health in occupational settings, it is important to characterise estimates of varying conditions in cross-sectional studies. The further understanding of its performance in longitudinal settings will also enhance its use.

\section{CONCLUSIONS}

Factors identified as important in the estimation of RVD in this group of miners included BMI, gas transfer impairment and spirometric acceptability criteria. High BMI was identified in a large proportion of the group and was strongly correlated with spirometry-identified RVD. Gas transfer impairment, in combination with spirometry, was likely helpful in more accurately identifying intrinsic RVD. Estimates for RVD also varied by spirometric acceptability criteria with more representative results occurring in those classified as 'usable'. These findings will be useful in future efforts to understand qualitative and quantitative exposure-disease relationships in these miners. 
Acknowledgements The authors would like to thank Leslie Studenski, Richard Hoffbeck for help with data management.

Contributors NUO and JHM conceived the idea of the research and were responsible for the design of the study. NUO conducted the data analysis and created the tables for the study. JHM, DMP and BHA provided input into the data analysis. NUO wrote the initial draft of the manuscript. JHM, DMP, BHA and PDS were involved with reviewing the research, interpreting the results and editing the manuscript. This involved repeated circulation among all authors for critical revision.

Funding This research was funded by the State of Minnesota.

Competing interests None.

Patient consent Obtained.

Ethics approval University of Minnesota Human Subjects Research Committee.

Provenance and peer review Not commissioned; externally peer reviewed.

Data sharing statement The University of Minnesota data sharing policy, data are not shared until final. The data are not considered final until the overall study effort is finished.

Open Access This is an Open Access article distributed in accordance with the Creative Commons Attribution Non Commercial (CC BY-NC 3.0) license, which permits others to distribute, remix, adapt, build upon this work noncommercially, and license their derivative works on different terms, provided the original work is properly cited and the use is non-commercial. See: http:// creativecommons.org/licenses/by-nc/3.0/

\section{REFERENCES}

1. Centers for Disease Control and Prevention. Workplace Safety and Health tips. http://www.cdc.gov/niosh/topics/spirometry/ (accessed 1 Jul 2012).

2. Jensen RL, Crapo RO, Enright P. A statistical rationale for the use of forced expired volume in $6 \mathrm{~s}$. Chest 2006;130:1650-6.

3. Wanger J, Clausen JL, Coates A, et al. Standardization of the measurement of lung volumes. Eur Respir J 2005;26:511-22.

4. Eisen EA, Dockery DW, Speizer FE, et al. The association between health status and the performance of excessively variable spirometry tests in a population-based study in six U.S. cities. Am Rev Respir Dis 1987;136:1371-6.

5. Miller MR, Hankinson J, Brusasco V, et al. Standardization of spirometry. ATS/ERS task force: standardization of lung function testing. Eur Respir J 2005;26:319-38.

6. Pelligrino R, Viegi G, Brusasco V, et al. Interpretative strategies for lung function tests. Eur Respir J 2005;26:948-68.

7. Venkateshiah SB, loachimescu OC, McCarthy K, et al. The utility of spirometry in diagnosing pulmonary restriction. Lung 2008;186:19-25.

8. Aaron SD, Dales RE, Cardinal P. How accurate is spirometry at predicting restrictive pulmonary impairment? Chest 1999;115:869-73.

9. D'Aquino LC, Rodrigues SC, de Barros JA, et al. Predicting reduced TLC in patients with low FVC and a normal or elevated FEV ${ }_{1} / F V C$ ratio. J Bras Pneumol 2010;36:460-7.

10. Vandervoorde J, Verbanck S, Schuermans D, et al. Forced vital capacity and forced expiratory volume in six seconds as predictors of reduced total lung capacity. Eur Respir J 2008;31:391-5.

11. Pezzoli L, Giardini G, Consonni S, et al. Quality of spirometric performance in older people. Age Aging 2003;32:43-6.

12. Rodenstein DO, Stanescu DC. Reassessment of lung volume measurement by helium dilution and body plethysmography in COPD. Am Rev Respir Dis 1983;128:54-9.

13. O'Donnell CR, Bankier AA, Stiebellehner L, et al. Comparison of plethysmographic and helium dilution lung volumes: which is best for COPD? Chest 2010;137:1108-15.

14. Punjabi NM, Shade D, Wise RA. Correction of single-breath helium lung volumes in patients with airflow obstruction. Chest 1998;114:907-18.
15. Enright P. Letter to the editor: FEV1 and FVC repeatability goals when performing spirometry. Prim Care Resp J 2010;19:194.

16. Petersen M, Castellan RM. Prevalence of chest symptoms in non-exposed blue collar workers. J Occup Med 1984;26:367-74.

17. Ferguson GT, Enright PL, Buist AS, et al. Office spirometry for lung health assessment in adults: a consensus statement from the National Lung health Education Program. Chest 2000; 117:1146-61.

18. Hansen JE, Sun XG, Wasserman K. Spirometric criteria for airway obstruction: use percentage of $F E V_{1} / F V C$ ratio below the fifth percentile, not \&lt;70\%. Chest 2007;131:349-55.

19. Akpinar-Elci M, Fedan KB, Enright PL. FEV 6 as a surrogate for FVC in detecting airways obstruction and restriction in the workplace. Eur Respir J 2006;27:374-7.

20. Vollmer WM, Gislason P, Burney P, et al. Comparison of spirometry criteria for the diagnosis of COPD: results from the BOLD study. Eur Respir J 2009;34:588-97.

21. Swanney MP, Ruppel G, Enright PL, et al. Using the lower limit of normal for the $F E V_{1} / F V C$ ratio reduces the misclassification of airway obstruction. Thorax 2008:63:1046-51.

22. Maclntyre N, Crapo RO, Viegi G, et al. Standardization of the single-breath determination of carbon monoxide uptake in the lung Eur Respir J 2005;26:720-35.

23. Hankinson JL, Odencrantz JR, Fedan KB. Spirometric reference values from a sample of the general U.S. population. Am J Respir Crit Care Med 1999;159:179-87.

24. Crapo RO, Morris AH, Gardner RM. Reference spirometric values using techniques and equipment that meet ATS recommendations. Am Rev Respir Dis 1981;123:659-64.

25. Dockery DH, Ware JH, Ferris BG, et al. Distribution of FEV1 and FVC in healthy, white adult never smokers in six U.S. cities. Am Rev Respir Dis 1985;131:511-20.

26. Knudson RJ, Slatin RC, Lebowitz MD, et al. The maximal expiratory flow-volume curve. Normal standards, variability, and the effects of age. Am Rev Respir Dis 1976;113:58-600.

27. Marion SM, Leonardson GR, Rhoades ER, et al. Spirometry reference values for American Indian adults: results from the Strong Heart Study. Chest 2001;120:489-95.

28. Glindmeyer HW, Lefante JJ, McColoster C, et al. Blue-collar normative spirometric values for Caucasian and African-American men and women aged 18 to 65. Am J Respir Crit Care Med 1995;151:412-22

29. Peterson M, Hankinson J. Spirometry reference values for non-exposed blue collar workers. J Occup Med 1985;27:644-50.

30. Hankinson JL, Kawut SM, Shahar E, et al. Performance of ATS-recommended spirometry reference values in a multiethnic sample of adults: the MESA Lung Study. Chest 2010;137:138-45.

31. Mead J. Dysanapsis in normal lungs assessed by the relationship between maximal flow, static recoil, and vital capacity. Am Rev Respir Dis 1980;121:339-42.

32. Stocks J, Quanjer PH. Reference values for residual volume, functional residual capacity and total lung capacity. Eur Respir $J$ 1995;8:492-506.

33. Saydain G, Beck KC, Decker PA, et al. Clinical significance of elevated diffusing capacity. Chest 2004:125:446-52.

34. Weibel ER. Morphometric estimation of pulmonary diffusion capacity. I. Model and method. Respir Physiol 1970-1971;11:54-75.

35. Cotes JE. Lung function assessment and application in medicine. 5th edn. Oxford: Blackwell Scientific Publishers, London, 1993:299-324.

36. Crapo RO, Morris AH. Standardized Single breath normal values for carbon monoxide diffusing capacity. Am Rev Respir Dis 1981:123:185-9.

37. Ferris BG. Epidemiology standardization project (American Thoracic Society). Am Rev Respir Dis 1978;118:1-120.

38. Miller MR, Hankinson J, Brusasco V, et al. Standardization of lung function testing: the authors' replies to readers' comments. Eur Respir J 2010;36:1496-8.

39. Vandervoorde J, Verbanck $\mathrm{S}$, Schuermans $\mathrm{D}$, et al. $\mathrm{FEV}_{1} / \mathrm{FEV}_{6}$ and $\mathrm{FEV}_{6}$ as an alternative for $\mathrm{FEV}_{1} / \mathrm{FVC}$ and FVC in the spirometric detection of airway obstruction and restriction. Chest 2005;127:1560-4.

40. Hegewald MJ. Diffusing capacity. Clin Rev Allergy Immunol 2009;37:159-66. 